\title{
¿Ya no sube el cortador contra nosotros! Interpretar la Biblia con conciencia ecológica
}

\begin{abstract}
Resumen
El artículo buscará unir crisis ecológica y texto bíblico en un ejercicio de interpretación, considerando textos selectos del Antiguo Testamento para responder a los problemas ya planteados. Se hará una breve síntesis en torno a algunos trabajos previos en hermenéutica ecológica, categoría dentro de la hermenéutica bíblica que ha asumido la ecología como sujeto hermenéutico. Luego, buscaremos soñar con la interpretación de dos textos, tal y como soñó el profeta Isaías, con el día en que podamos celebrar, junto con la creación entera, la caída de toda tiranía que tale y corte la vida.
\end{abstract}

Palabras clave. Hermenéutica Ecológica - Antropocentrismo - Dominación Colonial - Defensa de la Vida - Exégesis Narrativa -

\begin{abstract}
The article will seek to unite ecological crisis and biblical text in an interpretation exercise, considering selected texts of the Old Testament to respond to the problems that are planted. If there will be a brief synthesis of some previous work in ecological hermeneutics, it categorizes into the biblical hermeneutics that ecology has been assumed as a hermeneutic subject. Then, we will seek to unite with the interpretation of the texts, as well as only the prophet Isaiah, with the day in which we can celebrate, together with the creation in between, the fall of every tyranny that takes and cuts life.
\end{abstract}

Keywords: Ecological Hermeneutics - Anthropocentrism - Colonial Domination - Defense of Life - Narrative Exegesis

"Un texto biblico es una ventana. No miramos la ventana, sino a través de ella. Ese horizonte al que ella orienta nuestra mirada, no es la teología, sino la vida misma"

(Ramírez-Kidd)

"La actividad piñera descontrolada tiene una lógica excluyente en lo social y económico, y predadora en lo ambiental, y beneficia fundamentalmente a transnacionales y 
grandes capitales nacionales, profundiza la dependencia externa, promueve la concentración de la tierra y la proletarización del campesinado, y atenta contra la seguridad alimentaria de la región y del país en su conjunto ". (El Picudo, 2009: 7)

"No hay duda que el problema ecológico es un problema económico".(Roy May)

\section{1. ¿Por qué una mirada al problema ecológico? ¿Por qué desde la Biblia?}

La Biblia es aun hoy, en pleno siglo XXI, una tradición en disputa ${ }^{1}$. Como experiencia, y como herramienta, sigue leyéndose en diversos círculos para fomentar, por ejemplo, relaciones desiguales de poder, discursos y actos de exclusión y exclusivismo, y normalizar muchas prácticas de violencia. Por otro parte, hay interpretaciones que privilegian una mirada que permita la reflexión y construcción de sociedades justas, solidarias y hasta emancipadoras. Siendo que el texto es referente actual en temas de índole personal y social, y que su voz sigue siendo relevante para construir nuestra cultura, cosmovisión y proyectos de vida, es importante reflexionar a partir de éste, sobre uno de los problemas catalogados como urgentes de la sociedad actual: la crisis ecológica. Pero ¿por qué hablar del problema ecológico y de lo que la Biblia nos ofrece para abordar dicha situación?

El problema ecológico ha sido, desde la segunda mitad del siglo XX, la forma de describir los fenómenos climáticos "agresivos" provocados por el estilo de vida moderno. Esta forma de vida está vinculada, especialmente, al consumo descuidado de recursos naturales y a los cambios en los ecosistemas, producto tanto de este consumo como de la contaminación resultante, en gran medida, de los desechos de la producción industrial a gran escala. Dentro de un sistema de producción y consumo como éste, queda claro que no es la naturaleza, los ecosistemas o el clima, quienes evidencian únicamente las consecuencias y el daño provocado. El modelo, que parece producir de forma natural exclusión socio-económica, relaciones extractivistas con el medio ambiente y explotadoras para con quienes trabajan la tierra, monopolio de los recursos y el uso de violencia para conseguirlos, así como la usurpación del territorio y la contaminación del entorno, permite concluir que el llamado problema ecológico se convierte en un problema de organización social, con grandes consecuencias socio-ambientales que amenazan, en el peor escenario posible, la existencia.

La frase de El Picudo, citada al inicio del artículo, es el reflejo de un problema que va más allá del mal uso o la contaminación de los recursos. El problema, serio tal cual es, es uno del sistema, en este caso,

\footnotetext{
${ }^{1}$ Cf. Mosala, Itumeleng, Biblical Hermeneutics and Black Theology, 16-18 y 125. Este autor insiste en las distintas voces ideológicas en disputa, tanto en la interpretación del texto, pero más aún, en su misma composición y final contenido.
} 
del sistema económico. No hay duda que el problema ecológico es un problema económico. Por la forma en que dicho sistema roba la dignidad de la creación, convierte a sus miembros en objetos de cambio, mercancía y riqueza, creemos que su abordaje no es sólo urgente desde

las ciencias sociales, la política o la biología, sino que invoca, por su proyecto implícito², a la Teología y la Hermenéutica Bíblica.

El aspecto socio-ambiental y la importancia de los Estudios Bíblicos y la Teología para responder desde sus quehaceres a preguntas fundamentales de la existencia humana, plantean la necesidad de hacer una lectura bíblica en clave ecológica que incorpore en su análisis el rol de modelos económicos de carácter colonial como el aspecto más importante que genera ${ }^{3}$ la crisis.

Un proyecto colonial materializa usualmente sus intereses de riqueza y poder económico a través del uso de la creación como objeto de consumo y como una mercancía. El grito de la creación, provocado por la avaricia de poder y control de los recursos económicos victimiza y consume la vida animal, vegetal y humana, y es un elemento de nuestra realidad actual, una preocupación planteada de varias formas en las tradiciones bíblicas.

Si diéramos una mirada al contexto actual, veríamos cómo las consecuencias negativas del sistema económico mundial, que distribuye inequitativamente la riqueza disfrazándola de desarrollo y reactivación económica, son sufridas por los sectores más vulnerables de nuestras sociedades. Personas campesinas, indígenas, o de zonas urbanas marginadas, sin tierra o con bajos ingresos, ven sus aguas y aire contaminados, sus vidas condenadas a la esclavitud moderna, con bajos salarios y jornadas extenuantes, expuestas a venenos que contaminan y matan sus cuerpos junto con los de la naturaleza. En Costa Rica, Buenos Aires en Puntarenas y la zona de San Carlos, son ejemplos de esta explotación sistémica y con múltiples y diversas consecuencias, provocadas por empresas nacionales y extranjeras que ven en los recursos humanos y naturales su fuente de riqueza. La experiencia de vida en un entorno como este, según un periódico sancarleño que habla de la expansión de las plantaciones de piña y la vivencia de las personas en medio de ellas, queda reflejada en una frase

\footnotetext{
${ }^{2}$ Cf. Oliveros, Roberto, "Historia de la Teología de la Liberación", 18. El autor señala como punto de partida de esta teología "...la injusticia secular institucionalizada que somete a millones y millones a inhumana pobreza". Se deduce de aquí que el proyecto cristiano implica una crítica y transformación de realidades y sistemas opresivos.

${ }^{3}$ Cf. Ellacuría, Ignacio, "Historicidad de la Salvación Cristiana”, 355-357. Esto hace la Teología de la liberación al hablar sobre la injusticia económica. En esta cita, por ejemplo, el autor discute el concepto de pecado estructural, que él ve materializado en la injusticia social vivida por los pueblos latinoamericanos. Comprender los modelos sociales y políticos que "ejercen el poder en contra de los hombres" (Ellacuría, 356) se convierte en parte del quehacer bíblico- teológico.
} 
con tintes exódicos: a estas familias les toca atravesar "el desierto de la piñera". ${ }^{4}$

"Don Bernal", sobreviviente de las luchas llevadas entre los años /70s y /90s en Buenos Aires de Puntarenas contra una de las piñeras más famosas del país, recuerda que la batalla por los derechos del medio ambiente, la tierra y los campesinos fue dura. Cuenta cómo las amenazas, la persecución, y la intimidación fueron una constante, hasta que la compañía asumió algunas recomendaciones debido a las presiones de la comunidad y el gobierno. Hoy se lamenta de que nadie continuó la lucha: "hoy no hay organización", señala, "las personas siguen enfermas y explotadas, la tierra sigue tomada y contaminada, las aguas se convierten en botaderos, pero el movimiento ha sido desarticulado, pues mucha gente tiene miedo". El grito de dolor, el miedo por la persecución que se produce al levantar la voz por justicia, lleva no sólo a revisar cuidadosamente el mundo en que vivimos, sino que convoca, a quienes vemos el texto como una ventana ${ }^{5}$, a encontrar gritos similares en las diversas tradiciones bíblicas y tejer puentes entre dichas memorias y los problemas que enfrentamos actualmente.

Al leer "esta ventana", encontramos textos que han recuperado voces como las que se pueden escuchar hoy en Buenos Aires de Puntarenas. El profeta Isaías señala en boca de los cedros del Líbano: "desde que tú has caído, ya no sube talador contra nosotros" (Is 14.8b). Este verso evidencia no sólo la terrible experiencia de dominación político-económica ejercida por el imperio Babilónico (el tú del versículo no es otro que el rey de Babilonia), con consecuencias de impacto ecológico (¡son los cedros quienes celebran la caída del tirano!), sino que recuerda también el grito permanente por la liberación de sistemas que consumen y avasallan. La celebración de los pueblos y de la creación entera al soñar con la caída de los opresores, es más que razonable, urgente y actual.

A la luz de lo discutido, el artículo buscará unir crisis ecológica y texto bíblico en un ejercicio de interpretación, considerando textos selectos del Antiguo Testamento para responder a los problemas ya planteados. Se hará una breve síntesis en torno a algunos trabajos previos en hermenéutica ecológica, categoría dentro de la hermenéutica bíblica que ha asumido la ecología como sujeto hermenéutico. Luego, buscaremos soñar con la interpretación de dos textos, tal y como soñó el profeta Isaías, con el día en que podamos celebrar, junto con la creación entera, la caída de toda tiranía que tale y corte la vida.

\footnotetext{
${ }^{4}$ El Picudo, 7-8. Esta metáfora es sumamente sugestiva cuando se piensa desde el texto bíblico. El desierto donde hay agua amarga, el pan no cae del cielo, y la tierra se ha secado por la explotación. La gente, esclava, lo único que desea es salir de éste "sistema egipcio".

${ }^{5}$ En alusión a la cita del profesor Ramírez-Kidd, al inicio de este artículo.
} 


\section{Rostros de la Hermenéutica Ecológica}

A partir de los años 70, y de forma más sistemática, empiezan a surgir en el mundo académico bíblico-teológico, textos que refieren lecturas bíblicas "contextuales", esto es, que no se preocupan por indagar primeramente "el sentido original del texto en su contexto" según su potencial autor, sino por considerar como primer elemento interpretativo, los problemas y luchas de quienes leen, esto es, las preguntas primordiales en el contexto de recepción ${ }^{6}$. Diferentes problemáticas sociales de la época, por ejemplo, las luchas feministas de la segunda ola contra el machismo y el patriarcado, el paso de sociedades coloniales a realidades post y neocoloniales, los movimientos emancipatorios ante sociedades racistas y degradantes para con personas negras $\mathrm{u}$ orientales, indígenas y grupos LGTB, entre otros, hicieron surgir la necesidad de responder por el rol del texto en aquellas realidades, grupos y movimientos eclesiales y sociales vinculados a la Biblia.

Hermenéuticas bíblicas en clave feminista, postcolonial, de la negritud, indígena, LGTBI, o ecológica, ven su origen y primeros desarrollos, en una crítica al sistema que victimiza sus sujetos, y en la denuncia del rol opresivo de lo religioso en dichos sistemas. Proponen, finalmente, leer la Biblia como herramienta de identificación, consuelo y emancipación ${ }^{7}$. La hermenéutica ecológica se abrió camino en estos movimientos, colocando la creación como sujeto y preocupación de la interpretación bíblica.

\subsection{Presupuestos para una Hermenéutica Ecológica: Antropo- centrismo, Capitalismo y Dominación Colonial}

Las hermenéuticas contextuales aportaron discusiones sobre las estructuras y modelos que sustentaron las realidades opresivas a las que respondían. La hermenéutica latinoamericana, con su enfoque socio-político y económico, identificó al sistema capitalista como uno de los centros que explicaban el empobrecimiento y sometimiento de la mayoría de habitantes del continente. El movimiento bíblico-teológico feminista, por otro lado, explicó y criticó el sistema patriarcal como el encargado de dictar las relaciones y normas sociales que construyen desigualdad primeramente por causa de género. Dentro de la Hermenéutica Ecológica se acuña el antropocentrismo como la fuente de todos los males. Una cosmovisión antropocéntrica, fundamentada fuertemente en Occidente a partir

\footnotetext{
${ }^{6}$ Cf. De Witt, Hans. En la Dispersión el texto es Patria, 217.

${ }^{7}$ En las hermenéuticas contextuales o del genitivo tenemos hoy muy distintas agendas. Inicialmente la idea era la de recuperar el texto, debido a que estaba en manos de quienes sostenían discursos opresivos. Encontrar a mujeres, personas indígenas o empobrecidas, por ejemplo, y leer estas agendas desde otro proyecto, fue un movimiento reivindicador. Hoy la lectura ha cambiado, y se ha ampliado a nociones que incluso critican la validez de seguir leyendo el texto. Cf. De Witt, Hans. En la Dispersión el texto es Patria, p. 268 en adelante.
} 
del cristianismo tradicional, promueve la preponderancia del ser humano por sobre el resto de los seres y especies vivientes y la naturaleza.

Así lo señala Norman Habel, quien propone que una interpretación bíblica en clave ecológica implica reconocernos como "intérpretes occidentales y herederos de una larga perspectiva de lectura antropocéntrica, patriarcal y androcéntrica" que ha "devaluado la Tierra" 8 . Para este autor, coordinador del proyecto de lectura bíblica ecológica The Earth Bible ${ }^{9}$, existen cinco elementos de los que los y las intérpretes deben ser conscientes al momento de interpretar el Texto con conciencia ecológica: (1) reconocer la participación humana en la explotación y puesta en riesgo de la comunidad de la tierra; (2) reconocer que se es parte de esta comunidad de la Tierra que se encuentra en peligro; (3) reconocer la Tierra como sujeto en el texto bíblico y no como tema a analizar; (4) asumir la práctica de la Justicia para la Tierra y determinar cómo la tierra es oprimida, silenciada o liberada en el texto; y (5) finalmente, desarrollar formas de lectura y tradiciones alternativas que permitan leer el texto bíblico reconociendo la voz de la Tierra evidenciando su opresión ${ }^{10}$.

La Hermenéutica ecológica, según Habel, invita a lectores y lectoras a reconocerse, al menos de principio, como beneficiarios y victimarios del modelo de cosmovisión antropocéntrica. Traza así un mapa de lectura que implica reconocer los privilegios dados por el modelo, evidenciar la forma en que los seres de la naturaleza, convertidos en secundarios por el modelo antropocéntrico (que es primero androcéntrico, luego patriarcal, capitalista, etc.), han sufrido ante ellos, y buscar estrategias para evidenciar la injusticia proponiendo acciones para transformarla. La naturaleza, la creación, es ahora sujeto y no objeto, tanto en la sociedad como en una lectura bíblica en clave ecológica.

Habel insiste en que la hermenéutica ecológica debe reconocer toda la creación como víctima del modelo, idea que permite comprender la crisis ecológica ${ }^{11}$ como un problema que alcanza la vida como la conocemos, más allá de la naturaleza, incluidas las personas. $\mathrm{Al}$ momento de abordar el texto, y buscar en sus páginas sujetos del mundo animal o vegetal (la serpiente en Gen 3 y la burra de Balaam en Num 22, entre otros), se plantea el criterio de validación de lectura para con el texto bíblico: la justicia climática. Todo texto que atente contra el bienestar y promueva el abuso de la creación en cualquier forma de expresión, deberá ser descartado como modelo ético y teológico de vida. Desenmascarar los proyectos opresivos

\footnotetext{
${ }^{8}$ Habel, Norman, "Introducing Ecological Hermeneutics", 1-2.

${ }_{9}^{9}$ Para conocer más del Earth Bible Project visitar la página web: http: / / normanhabel.com/ ?page_id $=325$

${ }^{10}$ Habel, Introducing, 1-2.

${ }^{11}$ Cf. Zizek, Slavoj, Pedir lo Imposible, 6. El autor no piensa en una crisis ecológica tal cual, sino en que la naturaleza se encuentra en un constante caos.
} 
y evidenciar las metáforas que permiten lecturas emancipadoras, se convierte en la tarea de este quehacer.

El proyecto The Earth Bible, gestado mayormente en los salones de conferencias de la Society of Biblical Literature, y en el caso de Habel como reflexión desde el contexto australiano, plantea las contribuciones descritas así como algunos desafíos: sigue siendo muy occidental y racional en su comprensión del mundo y del texto, y corre el peligro de continuar construyendo dicotomías como humanidad - naturaleza, que no contribuyen a construir imaginarios de una creación integral.

Esfuerzos como los de Habel y su equipo han sido realizados también en países como Brasil, donde el biblista Luiz José Dietrich ha trabajado esbozando algunas pautas para leer la Biblia con conciencia ecológica. Algo que recupera Dietrich, y que no es mencionado por Habel, es que el problema ecológico no puede comprenderse sino como producto de un problema económico. Dietrich sostiene que ${ }^{12}$ :

"Lo que tenemos que entender es que la crisis social y la crisis ecológica que estamos viviendo brotan del mismo modelo de desenvolvimiento. Son intrínsecas al actual modelo de sociedad. Para el libre comercio, la libre circulación de las mercancías y el libre tránsito del capital, no interesa ningún tipo de regulación, sea de protección a los derechos laborales, sea de protección a las culturas y a los pueblos nativos y originarios, sea de protección ambiental. El actual modelo económico dirigido para la reproducción del capital devora tanto a las personas como a las cultura, tanto a los bosques como al patrimonio restante hídrico-natural" (Traducción del autor).

En lo que nos parece un abordaje propio de la Hermenéutica Bíblica Latinoamericana, Dietrich señala al modelo económico capitalista como el principal causante de la crisis ecológica que es parte íntegra de una crisis social. En su lectura, el interés económico pasa por encima de la seguridad y derechos de las personas y el ambiente. Encontramos así en Dietrich, un presupuesto clave en su lectura ecológica: el aspecto estructural de la economía como gestor de la crisis. La comprensión del modelo, los mecanismos que son parte de él, los rostros que lo sostienen y las víctimas que causa, se incorporan a la lectura bíblica en clave ecológica.

Dietrich esboza, junto con el modelo de opresión, alternativas de salida. Una idea de su hermenéutica es tener como criterio ideológico de lectura una conciencia de vida comunitaria vinculada al ambiente natural, que propugne un pensamiento holístico y que "busque en las sabidurías, espiritualidades y organizaciones tradicionales, formas alternativas de vivir y relacionarse con la naturaleza"13. Junta a esta restructuración de la vida y las relaciones sociales - muy popular en algunos espacios que

\footnotetext{
${ }^{12}$ Dietrich, Luiz, "Pautas para una Hermenéutica Ecológica", 79.

${ }^{13}$ Ídem.
} 
insisten en una vuelta a las cosmovisiones y formas de vida de pueblos ancestrales, pero que debe ser vista con criticidad para evitar cualquier tipo de idealismo acrítico -, Dietrich postula que también es necesario "preguntar a la Biblia por la contribución que ella puede dar"14. Esta pregunta es importante, entre otras razones, para concientizar sobre la necesidad de aproximarse no con respuestas elaboradas de forma anticipada, sino sopesando si el texto tiene algo que ofrecer al tema en cuestión desde la perspectiva asumida.

La pregunta por el rol de la Biblia no puede ser tomada como inocente. Según autor, algunos grupos indígenas del Brasil - a los que considera modelos de convivencia holística con el entorno-, ven en la Biblia "una de las grandes culpables por la relación utilitarista y destructora adoptada por la civilización occidental para con la naturaleza"15. Para estas personas, argumenta el autor,

"la Biblia, al acentuar demasiado el papel del ser humano - entiéndase aquí al hombre blanco, judeo-cristiano y europeo - como señor de la creación (Gen 1.26, 28), justificó y legitimó la violencia contra pueblos y culturas profundamente respetuosos de la naturaleza... [esto fundamentó]... la construcción de una mitología del poder... todo siempre en nombre del 'progreso y del desenvolvimiento' de la humanidad occidental cristiana"16.

El rol negativo de la Biblia es abordado en bastantes ocasiones por las hermenéuticas contextuales, debido a que muchos de los problemas que estas abordan (patriarcado, explotación y dominación económica, racismo, colonialismo, etc), han tenido sustentos teológicos desde el texto. Para Dietrich es importante iniciar reconociendo el papel de la Biblia en el problema ecológico, que se vincula, según la visión de los pueblos originarios con los que dialoga, con un proyecto colonial. La legitimación del ser humano como centro, señor y dominador de la creación, y dentro del ser humano, de sujetos que alcanzan la capacidad de dominar su entorno, se señala aquí como uno de los aspectos que han sido tomados de la Biblia y que han promovido la violencia contra pueblos y naturaleza. Este último aspecto refuerza la idea de que la crisis ecológica es una de las consecuencias de diversos proyectos de índole colonial o de dominación, para extraer el máximo provecho económico de los distintos seres y elementos que componen la creación y la naturaleza.

\footnotetext{
14 Ídem.

${ }^{15}$ Ibíd, 80.

${ }^{16}$ Ídem.
} 


\subsection{Hermenéutica ecológica como defensa de la vida: la idea de Palabra de Dios}

A partir del cuestionamiento a la Biblia por su rol en la construcción de dinámicas de dominación, Dietrich esboza cinco ideas fundamentales al momento de leer la Biblia con conciencia ecológica. Para que un mundo diferente sea posible, argumenta, la hermenéutica debe considerar: (1) la historia del pueblo de Israel y de la redacción de los textos bíblicos; (2) lo que constituye la Palabra de Dios; (3) la gran tela de interrelaciones que es la Vida y nuestro lugar en ella; (4) la Ecología como solidaridad planetaria; y (5) la militancia profética, ecuménica y práctica en el cuidado, la defensa y el amor a la Vida ${ }^{17}$.

Tres de estas cinco pautas de Dietrich, se diferencian claramente de las propuestas de Habel. Podríamos decir que la pauta tres y la cinco apelan a dos aspectos ya mencionados: (a) reconocer la relación integral y holística entre los seres creados como aspecto fundamental, no sólo de lectura sino de relacionamiento; (b) la necesidad de practicar la justicia en beneficio de la vida en todas sus expresiones. Hablaríamos pues, de cosmovisión primero, y de proyecto de acción en segundo lugar.

Los puntos 1, 2 y 4 del autor son la novedad del aporte hermenéutico, y apelan al uso de herramientas exegéticas y a discusiones teológicas. El punto 1, que alude al quehacer más tradicional de la Hermenéutica Bíblica Latinoamericana, busca priorizar los aspectos materiales, sociales e históricos tanto del texto como de la comunidad lectora. A través de una exégesis que utiliza las herramientas de la sociología y la historiografía entre otras, Dietrich señala que es importante ubicar social e históricamente el mundo de producción de los textos, mundo que alberga distintos grupos sociales en tensión, y por ende, distintas apuestas teológicas. En lo que parecen ser referencias a trabajos clásicos de exégesis sociológica de autores como N. Gottwald ${ }^{18}$ y W. Brueggeman ${ }^{19}$, se insiste en que colocar los textos en su posible contexto de origen permitirá ver, ideológicamente, si hay fecundidad para una lectura "ecológicamente liberadora". Dietrich parece partir aquí de una práctica de hermenéutica latinoamericana popular especialmente en los años / 80, la cual buscaba indagar en los posibles intereses ideológicos originarios de los diversos textos, y medir hasta qué punto estos correspondían con los proyectos ideo-teológicos de la comunidad lectora. Para Dietrich, este ejercicio permitirá discernir la ruah del texto, esto es, porciones de la Escritura que permiten construir proyectos de vida ${ }^{20}$.

En su interpretación al texto de Génesis 1,1-2,4, texto utilizado tradicionalmente para fomentar la dominación por parte del ser humano del

\footnotetext{
${ }^{17}$ Ídem.

${ }^{18}$ Gottwald, Norman, The Tribes of Yhwh, 210, 489, y 700.

${ }^{19}$ Brueggemann, Walter, “Trajectories and Trends", 201-205.

${ }^{20}$ Dietrich, Pautas, 81.
} 
resto del mundo creado, Dietrich recupera los dos versos en los que se insiste en "subyugar" y "dominar" $(\mathrm{Gn} 1,26)$. Su primer aporte interpretativo, fiel a su método, es suscitar el vínculo con la monarquía ${ }^{21}$. Esto, nos parece, es una estrategia para deslegitimar la idea de dominación del texto, vinculándolo histórica y sociológicamente a un proyecto que no sería afín ni a sus principios religiosos ni a los que considera vinculados con la ruah en el texto. Aunque la importancia de los elementos históricos y sociológicos en la comprensión del contenido teológico del texto es reconocida-inclusive será una herramienta a utilizar en la lectura que se hará aquí de Isaías 14 -, la apropiación del texto ya no dependerá, necesariamente, de que haya consonancia entre el proyecto ideo-teológico o potenciales intensiones "originales" y las de la comunidad lectora actual, como se pretendió en cierto momento.

Otro de los conceptos que sugiere Dietrich en su lectura con conciencia ecológica es el de Palabra de Dios. Siendo que su aproximación al texto recupera las dinámicas coloniales en la historia moderna, el autor insiste en que,

"Cuando las narrativas bíblicas son usadas para condenar tradiciones religiosas o culturales de otros pueblos, o cuando sirven de legitimación para la destrucción de otros pueblos, como aconteció en la confrontación de la civilización blanca con las civilizaciones africanas y americanas, ellas dejan de ser Palabra de Dios"22.

Este aspecto no puede deslindarse de lo discutido anteriormente. Para Dietrich es importante que los horizontes ideo-teológicos del texto, no impliquen la destrucción, la violencia y la dominación "del otro", como argumentó en su lectura de Gen 1,26. Tal y como se hizo en la hermenéutica latinoamericana, feminista, indígena o afro, cualquier texto que promueva el robo de su dignidad deja de ser reconocido como Palabra divina. Por ende, otro de los presupuestos básicos de la lectura bíblica con conciencia ecológica es el de denunciar textos que deben ser catalogados como antítesis de la Palabra Divina, esto por la ética de violencia y dominación que fomentan para con los seres y elementos de la creación. En este punto el autor es categórico, y sostiene que la Biblia no podrá ser palabra de Dios hoy, si nos hace "callarnos ante la acción de aquellas fuerzas que destinan millares de personas a la muerte por hambre, sed, miseria, dolencia y exclusión, y devoran la vida natural" ${ }^{23}$.

Queda claro que el criterio de lectura de Dietrich implica que el ser humano y la naturaleza son uno sólo, y que cualquier sistema que pro-

\footnotetext{
${ }^{21}$ Ibíd, 82. J. Rogerson en su trabajo Genesis 1-11 (p.15-16), desde los 80s este verso se lee con implicaciones ecológicas. En su síntesis, expone como N. Lohfink insiste en que una lectura que sustente la dominación humana; en dicha sección no concuerda con el interés en el texto.

${ }^{22}$ Ibíd, 83.

${ }^{23} \mathrm{Ibíd}, 83-84$.
} 
mueva una condición de abuso e instrumentalización e ellos, deberá ser denunciado como algo que no pertenece a la revelación divina. Es interesante aquí el aporte del autor, que recurre a la tradición de hermenéutica latinoamericana para colocar la problemática a niveles estructurales o sistémicos, y cuya visión de conciencia ecológica recupera la naturaleza y al ser humano como víctimas de la crisis.

La antítesis de una lectura que fomenta el hambre, el dolor y la destrucción es la que llama a una interpretación "en función de la vida" ${ }^{24}$. El autor se mueve y utiliza la figura de Jesús como pauta hermenéutica para este tipo de lectura. Dietrich insiste en que "una hermenéutica ecológica necesita que leamos la Biblia con una perspectiva semejante a aquella con la que Jesús interpretó el sábado (Mc 2,27)”25. Pero ¿qué significa esto? El autor explica su comprensión de las palabras de Jesús al mencionar que "El sábado debe ser observado en función de la Vida. El valor absoluto debe estar en la defensa de la Vida y no en el sábado". Con este juego de palabras en torno a lo que anota el evangelio de Marcos, Dietrich expone cómo una hermenéutica liberadora y ecológica debe sopesar toda relación social, narrativa, todo discurso y toda práctica, dentro y fuera del texto, y concluir hasta qué punto "están al servicio de la vida, de todas las formas de vida" ${ }^{26}$. Las palabras de Dietrich son un eco de la tradición de los movimientos hermenéuticos de liberación, y del trabajo de Habel mismo, quien insiste en sospechar del discurso antropocéntrico de dominación, identificarse con quienes sufren, resisten o están excluidos en el texto - lo que se llamó lectura en solidaridad con-, para finalmente tomar postura ${ }^{27}$ leyendo y actuando en sintonía con la lucha por la eco-justicia.

En este ejercicio la persona se comprende como parte de un universo, vinculada por una serie de interrelaciones e interdependencias respecto de las otras partes de la creación ${ }^{28}$. Para Dietrich "una forma de vida no se separa y no existe sin las otras ${ }^{\prime 2}{ }^{29}$. Esta noción de integralidad o relación holística debe ser parte fundamental como presupuesto de la hermenéutica ecológica, entrando en tensión con una "interpretación bíblica y tradición de las iglesias fundada en la dicotomía" ${ }^{\prime 30}$, que ha dividido, entre otras, la cultura y la naturaleza. Construir e insistir en torno a la consecución de la gran Comunidad de la Tierra será la agenda de la lectura con ciencia ecológica.

\footnotetext{
${ }^{24}$ Ibíd, 84 .

${ }^{25}$ Ídem.

${ }^{26}$ Ídem.

${ }^{27}$ Cf. Mosala, Biblical Hermeneutics, 27. El "tomar postura" es una de las ideas en que más insiste el biblista sudafricano Mosala al hacer Hermenéutica Liberadora, debido a las distintas ideologías que se perciben en los textos.

${ }^{28}$ Dietrich, Pautas, 86.

${ }^{29}$ Ídem.

${ }^{30} \mathrm{Ibíd}, 87$.
} 
3. Ejemplos de lectura bíblica en clave ecológica: Génesis 2,43,24 e Isaías 14,3-8

A la luz de los aportes de Habel y Dietrich, haremos una lectura de Génesis 2,4-3,24 e Isaías 14,3-8, ilustrando algunos aspectos que pueden ser fructíferos para una lectura ecológica y liberadora.

\subsection{Génesis 2,4-3,24: Un Adam para cultivar la tierra}

Utilizaremos los elementos de estructura, personajes y repetición pertenecientes a la exégesis narrativa ${ }^{31}$, para esbozar algunas ideas de interpretación de este texto en clave ecológica. El texto, cuando se lee a partir de los repetidos encuentros entre dos personajes, Adam (ser humano/ hombre) y Adamah (tierra/suelo), puede ilustrar una relación de vinculación íntima entre dos elementos de la creación, rota finalmente, por el avance abusivo de uno por sobre la otra. La secuencia de eventos que se narra en el texto, permite ver la relación entre ambos miembros de la naturaleza:

A. Un Adam tomado de Adamah: intimidad y cercania entre dos seres vivientes (Gen 2,4-14).

B. Un Adam para cuidar y cultivar la tierra: la vida humana para ligada "al otro" (Gen 2,15).

C. Un Adam que tiene todo lo que necesita: cada fruto del jardín (Gen 2,16-3,7).

$C^{\prime}$.Un Adam que toma más de lo que necesita: $\underline{\text { el fruto del }}$ conocimiento (Gen 3,8-13).

B.' Un Adam que maldice la tierra: espinos y cardos... comeràs con fatiga (Gen 3,14-19).

A'. Un Adam que pierde la tierra: expulsado del jardín (Gen 3,2024).

La secuencia de escenas que muestra esta estructura, permite ver como una lectura ecológica de Génesis 2,1-3,24 narra una desvinculación progresiva de los seres de la creación Adam-Adamah, al inicio uno sólo. En un principio, según la sección A., tenemos la elaboración que hace Yahvé del Adam a partir de Adamah (Gen 2,4-14). El vínculo entre los dos

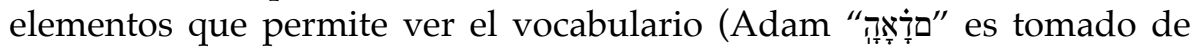

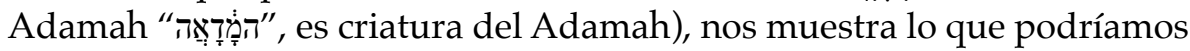
considerar pertenencia: Adam es tomado de esa tierra, y a esta volver;a cuando llegue el día. Ambos seres están juntos y vinculados al inicio del relato.

La intimidad y relacionamiento de la tierra y el ser que brota de ésta, se estrechan en el siguiente evento. En el apartado B., es Adam quien ejer-

${ }^{31}$ Ver por ejemplo S. Bar Efrat, El Arte de la Narrativa en la Biblia, 117-178. 
ce ahora acción sobre Adamah. Yahvé le asigna la responsabilidad de cuidar y cultivar la Adamah del jardín. ¿Cómo entender las acciones de cuidar y cultivar? Ambas pueden ser vistas como una misma cosa desde una aproximación ecológica. El encuentro de Adam con Adamah al cultivar, debe permitir un encuentro que genere fruto. Dicho fruto será el testigo de la vida de Adamah - que cumple su rol de dar vida desde la tierra - y al mismo momento, con dicho fruto, sustenta la vida de Adam. El verbo guardar "רמש" implica vigilancia (1 Sam 17,20), cuidado (Sal 121,7) y protección (Est 2,3), lo que suscita una situación de responsabilidad-cercanía entre Adam y Adamah. Ambos elementos siguen ligados aún, y mientras que uno brotó de la otra, ahora la otra deberá ser cuidada y atendida por el primero. Dicho equilibrio garantizará, para ambos, la vida.

Con dicha organización de las cosas sigue el tercer momento, C., donde Adam se encuentra poseyendo todo lo que necesita para vivir. Así lo dice Yahvé-Elohim, quien manifiesta que Adam puede disponer de todos los árboles del huerto. La sección 2,16-3,7 narra la vida en plenitud, donde la relación armoniosa entre Adam y Adamah en el jardín garantiza que se disponga de todo para disfrutar la vida. Adam lo tiene todo. Ese mundo de Edén ofrece lo que el ser humano necesita en plenitud, y ¿no es igualmente hoy, cuando la comida del mundo alcanza para toda la población, aunque muchos y muchas mueren de hambre?

Hasta la sección 3, nadie tiene hambre, pues se ha garantizado que haya todo lo que se requiere para vivir. Pero la sección 4 prepara un evento que suscita un giro en las relaciones Adam-Adamah, con consecuencias trágicas. En $\mathbf{C}^{\prime}$.,Adam, que tiene todo según $\mathbf{C}$., quiere más, y toma lo que no necesita. Gen 3,8-13 narra la insistente práctica del ser humano de tomar más allá de lo que necesita. Esta práctica de extracción innecesaria, que no busca cubrir necesidades y producir bienestar, sino que se excede en lo que refiere a tomar de la compañera con quien se cohabita, arruinará la relación armoniosa existente. Estamos en el centro del relato, y C. / $\mathbf{C}^{\prime}$. permiten contraponer la esencia del Adam que tiene todo y vive en armonía con Adamah, con el Adam que toma más de lo que necesita de Adamah, y rompe así su relación con todo lo que le rodea.

$\mathrm{B}^{\prime}$. nos describe las consecuencias que trae el tomar más allá de lo necesario. Génesis 3,14-19 muestra que, de la relación de cuidado recíproco que permite la vida en B., pasamos ahora a una realidad antagónica. El alimento de la cosecha ya no brotará con alegría, sino con sudor; el fruto no será dulce y abundante, sino espinoso y amargo. Adamah, quien dio todo lo que tuvo, todo lo que Adam quiso, ya no tiene nada qué dar. No hay comunión de vida entre Adam y Adamah, agotada la segunda por la insistencia de Adam de tomar todo. Adam es acusado de maldecir la tierra, y la tierra maldita es una maldición para Adam, que vive de ella, con ella, por ella. Lo que era armonía, alegría, y reciprocidad, se ha convertido en sequedad, escasez y ruptura. 
Finalmente, el ciclo de este relato cierra con la separación definitiva de quienes en su momento fueron uno. Adam es expulsado del jardín, de Adamah, o más bien expulsado por ésta. No hay forma de que, por la actitud de Adam, Adamah pueda seguir albergándolo. Adam se ve forzado a abandonar el lugar al que pertenece, en que descansa su esencia, de donde brota su vida. Su acto ha tenido grandes consecuencias, separándolo de Yahvé, de su compañera y de la Tierra. La armonía termina con violencia: la tierra expulsará a Adam, forzando una separación dónde ya no se puede sostener la unidad. El relato de la expulsión, a la luz de una lectura ecológica, podría tener una moraleja clara: la tierra no podrá soportar para siempre un Adam que toma lo que no necesita. Tarde o temprano, el fruto dulce se convertirá en espino amargo.

Una lectura con mirada ecológica, siguiendo los elementos esbozados por Habel y Dietrich, además de otras intuiciones, permite colocar la mirada en la integralidad y reciprocidad de la creación, ejemplificadas aquí por el binomio Adam-Adamah. Así como Dietrich y Habel insisten en la necesidad de asumir una perspectiva holística en la experiencia de crisis ecológica, donde ser humano y naturaleza son una sola cosa interdependiente, necesario el uno para la otra y viceversa, el texto deja ver una relación similar, donde Adam y Adamah se necesitan mutuamente para garantizar la vida y el bienestar de ambos.

Por otro lado, una lectura que coloca no sólo al ser humano sino también a otros elementos de la creación, como Adamah en este caso, permite recuperar las voces y experiencias de todos los sujetos importantes dentro de la hermenéutica ecológica. Adamah es parte activa del relato del jardín, y al final se distancia de la criatura a la que ha permitido la vida. Finalmente, el texto permite criticar, en términos sistémicos, toda cultura extractivista y abusiva en la relación ser humano-naturaleza. El abuso de Adam en la toma de los recursos que Adamah ofrece, lleva únicamente a la muerte de la tierra, que ya no puede dar fruto bueno, solo cardo y espino. Adam experimenta consecuencias fuertes por sus actos; le será más difícil y agotador conseguir lo que necesita para seguir viviendo; finalmente, será expulsado de la realidad y el espacio a los que perteneció. El texto, de carácter etiológico y sapiencial, es una advertencia en distintos niveles. En términos ecológicos, indica el cuidado que se debe tener en la forma en la que los seres humanos se relacionan con su entorno. Una relación abusiva no será tolerada por Yahvé, y la consecuencia de una acción de ese tipo será la expulsión final de la vida humana.

\subsection{Isaías 14,3-8: ¡Cómo ha acabado el tirano!}

El segundo ejemplo de lectura ecológica en este trabajo discute el texto de Isaías 14,3-8. Dicho texto puede ser visto en cuatro momentos principales: 
A. Cántico contra el rey de Babilonia: ¡Cómo ha caído el tirano! (Is 14,3-4).

B. El que golpeaba con furia, el que con ira oprimía $(14,5-6)$.

B' $^{\prime}$ La tierra descansa! $(14,7)$.

A'. ¡Cántico contra el rey de Babilonia: ya no sube quien nos hacía caer! $(14,8)$.

La estructura de este texto permite mirar la experiencia de los seres de la creación ante un sistema socio-económico y político imperial. El primer momento, localizado en $\mathbf{A}$ (Is 8,4), presenta la voz del narrador haciendo referencia a la condición de vida bajo el régimen del rey de Babilonia. La palabras utilizadas en el verso 3 (penas, temores, y dura servidumbre), pertenecen a un mismo campo semántico que refleja la situación anti-vida mencionada en los presupuestos esbozados por Dietrich anteriormente. La frase "dura servidumbre" es paradigmática y transporta a la comunidad que escucha, a la experiencia de Egipto (ver Éx 1,4), evocada sin duda en este texto por un nuevo imperio: Babilonia.

Si seguimos uno de los principios interpretativos de Dietrich, que coloca la importancia de la investigación social e histórica del texto para localizarlo en su posible contexto de origen, vemos que el texto tendría una ubicación cronológica tardía, relacionada probablemente con el Exilio (la mención de Babilonia sería el indicador más claro al menos a nivel literario $^{32}$. La dominación babilónica es importante, tanto a nivel simbólico como concreto, para explorar una lectura ecológica. Croatto explica que el texto de Isaías 14, aunque menciona al rey de Babilonia, podría reflejar una época posterior, como por ejemplo, la vida bajo el rey persa ${ }^{33}$. Esta mención revela para este autor un aspecto simbólico poderoso: la referencia de Isaías no sólo aplica a Babilonia o Persia, sino a cualquier otro imperio hasta nuestros días ${ }^{34}$. Esta perspectiva de Croatto abre un horizonte hermenéutico importante para que este texto siga siendo simbólicamente fértil en nuestro contexto.

La invitación a entonar una sátira contra este rey, se hará real en un momento concreto: cuando reposes de penas y temores, de la dura servidumbre que has servido. Así se adelante aquí el canto ${ }^{35}$, pero ¿cómo se materializa esa dura servidumbre? Veremos en el desarrollo del texto que la dominación imperial tiene mucho que ver con los problemas que nos convocan en términos ecológicos. El contenido del cántico, inicia en A.,

\footnotetext{
${ }^{32}$ S. Croatto, La vida de la Naturaleza en Perspectiva Bíblica, 49.

${ }^{33}$ Ídem.

${ }^{34}$ Ídem.

35 "Adelante" en términos de la forma literaria del texto profético. El texto se ambienta en un momento antes de la caída, pero la composición del texto, como mencionamos, es probablemente posterior.
} 
donde a través de un paralelismo, se insiste en el fin del régimen que trae pena, temor y dura servidumbre:

\section{ha acabado el tirano}

\section{ha cesado su agitación}

Lo que queda claro en el canto es que el sufrimiento del pueblo ha terminado. Ahora, en dicho canto la celebración tiene un fuerte sentido: recordar los actos del tirano caído. La sección B, en Isaías 14,5-6, el actor principal es Yahvé, quien actúa en favor de su pueblo. La acción concreta es contra el tirano, reflejado en la figura de los malvados/dominadores. Con un paralelismo, el profeta insiste en que Yahvé quiebra el símbolo de poder (cetro/vara) de los malvados, esto es, de quienes dominan por sobre otros. El texto, se puede decir, es una crítica al sufrimiento colonial de Israel a manos de imperios extranjeros. El despojo del tirano es también espejo de su actuar: se impone con cetro, es malvado y dominador. En el verso 6 encontramos el tercer paralelismo, que describe con claridad el ejercicio del poderoso:

"al que golpeaba furioso a los pueblos con golpes incesantes

y oprimía iracundo a las naciones con opresión implacable." (Is 14,6 BP)

El tirano se describe aquí por lo que hace: golpear con furia a los pueblos, oprimir iracundo a las naciones con opresión implacable. El texto es muy gráfico. Los golpes son constantes, la opresión es implacable, no perdona ni discierne. Pero ¿a dónde se dirigen estos golpes? ¿Quienes sufren esta ira implacable? Ante la furia del dominador, la sección $\mathbf{B}^{\prime}$. hace el contraste con la realidad cuando éste haya caído. En 14,7a la tierra descansa, esto por la caída mencionada anteriormente. Cuando cae el sistema de opresión, la Adamah, casa y fuente de vida de Adam, puede descansar y celebrar. El grito de júbilo en $7 \mathrm{~b}$ atestigua la nueva situación. En la interpretación ecológica es importante identificar aquellos sujetos pertenecientes a la creación que no implican únicamente al ser humano. Aquí tenemos el estado de Adamah, víctima de los golpes duros, irascibles, implacables del opresor imperial y la voz de quienes celebran su caída. Las secciones B. y B'. muestran el cambio en la situación. De la furia y a ira de la opresión, al descanso y júbilo de la tierra.

La última sección, en $\mathbf{A}^{\prime}$. (14,7b-8), hace más evidente el golpe duro del tirano a los seres de la naturaleza. El grito de júbilo de la Adamah es secundado por la voz de los cipreses y los cedros. Los primeros se alegran de la suerte del tirano, y los segundos hacen en su canto una acusación concreta: desde que yaces tendido, ya no sube cortador contra nosotros. La contraposición de la frase es magistral: ya nadie tiende a los cedros desde que el tirano yace tendido. Las imágenes, y la construcción de espacio, dejan ver la inversión de situación. No es el tirano quien dirige su 
mirada a los cedros caídos, son los cedros, quienes desde sus copas, ven al rey-opresor tendido. La voz final, donde los árboles celebran la caída del rey de Babilonia, nos lleva de nuevo a nuestra discusión inicial, donde insistimos en que el tema de la crisis ecológica tiene raíces socio-políticas y económicas. Los proyectos de índole colonial e imperial, son una amenaza para la paz de la tierra toda.

Es importante, desde el contexto del texto, esbozar algunas ideas de las consecuencias de los proyectos coloniales en la vida de la naturaleza. Croatto, en su trabajo sobre Isaías 14, indica que el verso 8 no puede entenderse como "...una frase puramente poética" ${ }^{36}$. Croatto indica que no es extraño que la voz que se levanta a la caída del tirano es la de los cipreses y cedros, recursos codiciados en el antiguo cercano Oriente por su utilidad en la construcción. Eran recursos cotizados y caros, suficientemente atractivos para llevar a cabo un proyecto militar, como el petróleo hoy, por ejemplo. Croatto sugiere que:

“La alegría expresada por los cipreses y los cedros (8a) deja atrás una experiencia trágica, cual es la destrucción de la flora más apreciada en las regiones montañosas de los montes Líbano y Amanus. Que el poeta, que habla de Judá, aluda a árboles típicos de otras zonas de Canaán, es indicio de que éstos son ejemplos "paradigmáticos", que valen para toda clase de devastación de la flora con intereses económicos desmedidos y extraños" ${ }^{37}$

La voz de los cedros y cipreses evoca la experiencia de colonización sufrida por muchos pueblos, Judá incluido. Para Croatto, una de las razones importantes para la tala de estos árboles, se debe al interés económico de los príncipes de antaño, unido al deseo de dominación que conlleva el eliminar las fuentes de sustento de pueblos sitiados. D.H. Mayes señala que "Israel compartía con muchos otros la práctica común de destruir los recursos naturales de vida en un país invadido por sus ejércitos" ${ }^{\prime 3}$. El texto de Deut 20,19 es una ventana para mirar esta realidad:

19 "Si tienes que sitiar largo tiempo una ciudad antes de tomarla al asalto, no destruyas su arbolado a hachazos, porque podrás comer de sus frutos; no los tales, porque los árboles no son hombres para que los trates como a los sitiados". (Deut. 20:19 BP)

Mayes plantea que “La prohibición aquí es una protesta deuteronomística en contra de una práctica considerada innecesariamente destructiva" ${ }^{39}$. El texto permite corroborar que la información de Isaías sobre la victimización de la naturaleza en los conflictos bélicos y de dominación,

\footnotetext{
${ }^{36}$ Croatto, La vida de la Naturaleza, 50.

37 Ídem.

${ }^{38}$ Hasel, The Destruction of Trees, 199.

${ }^{39}$ Ídem.
} 
era bien conocida. La madera de los árboles era usada igualmente para construir máquinas de asalto ${ }^{40}$, y muchas de las leyes de prohibición estarían pensando en las tácticas de guerra asirias y babilónicas, reflejando el contexto socio-político entre los siglos VII y $\mathrm{V}^{41}$, contexto de composición de Isaías 14.

Documentos asirios y babilonios de la época del Antiguo Testamento, están llenos de referencias que vinculan la práctica de la dominación política con la destrucción del entorno natural. Hasel menciona que, según los anales asirios, en el año 18 de Salmanasar éste rey marchó contra Hazael de Aram y cortó sus jardines frutales ${ }^{42}$. Este autor también menciona que en los anales de Suhu, los líderes de ciertas tribus arameas se organizaban para hacer guerra contra la tierra de Suhu ${ }^{43}$. Los líderes decían: "Iremos y atacaremos las casas de la tierra de Suhu; tomaremos sus ciudades de la estepa, y cortaremos sus árboles frutales" ${ }^{\prime 4}$. La tierra de Suhu es mencionada en el Obelisco Negro de Salmanasar III, dónde cinco palmas sirven como escenario de fondo ${ }^{45}$. Finalmente, también Hasel menciona que en su 4ta campaña, Shamshi-Adad V (823-811 a.e.c.), hijo de Salmanasar III, dice sobre las ciudades de Datebir e Izduia: "Sus plantaciones yo corté; sus ciudades yo destruí, devasté y quemé con fuego" ${ }^{\prime 4}$. Las razones para esta destrucción son diferentes, la finalidad en este caso era la de destruir el sistema de supervivencia de los habitantes; castigar a los habitantes por rebelión; alimentar los ejércitos invasores; hacer memorable una conquista o la necesidad de construir máquinas de asalto. Todas estas son parte de estrategias de control y dominación, donde la naturaleza en especial gime.

Otro ejemplo, finalmente, lo podemos ver en 1 Re 4-6, donde Salomón contrata a Hiram de Tiro para que corte árboles, los traiga a Jerusalén, y lleve a cabo la construcción del templo-palacio. Aquí vemos por qué razón se cortaban los árboles: el modelo de estado monárquico requiere recursos para construir grandes ciudades y monumentos. Los cedros del Líbano son también, a la luz de estos textos, mercancía preciada para el comercio.

Podemos decir que Isaías 14,3-8 brinda un terreno fértil para hacer un ejercicio en clave ecológica. Su lectura permite ver la voz que se levanta de los cedros y la tierra, que celebran y denuncian la violencia imperial y colonial que les daña y acaba. La caída del tirano representa descanso, paz y júbilo para la tierra. Detrás del texto tenemos violencia imperial,

\footnotetext{
${ }^{40}$ Ídem.

${ }^{41}$ Ibid, 200.

${ }^{42}$ Ibid, 202.

${ }^{43}$ Ídem.

${ }^{44}$ Ibid, 202-203.

${ }^{45} \mathrm{Ibid}, 203$.

${ }^{46}$ Ídem.
} 
dominación y conversión de la naturaleza en mercancía. El sueño de ver caer al tirano, es un sueño que liberará de esclavitud a toda criatura.

\section{Conclusiones}

El presente artículo ha tenido el interés de discutir algunos aspectos de importancia a considerar al momento de realizar lecturas ecológicas del texto bíblico. Primero, fue importante posicionar, a la luz de algunos aspectos de la vida real en Costa Rica, la complejidad de problemas que pueden ser entendidos como crisis ecológica. La contaminación del ambiente y la explotación de la tierra y las personas, están incluidas en prácticas que lesionan la armonía de la naturaleza. Esto nos lleva a hablar de crisis ecológica desde una crítica al modelo económico, que tiene una relación extractiva y exhaustiva con los elementos de la naturaleza para producir beneficios económicos.

Desde la hermenéutica ecológica, hemos dado un vistazo a algunas propuestas basadas en los trabajos de Habel y Dietrich. La idea de sospechar de las posturas antropocéntricas, tanto dentro del texto como desde la comunidad que lo lee, es una de las primeras sospechas. Es necesario dejar de hablar de ser humano - naturaleza, y construir comprensiones holísticas que permitan ver y buscar soluciones para los problemas de forma integral. La perspectiva de la vida es el criterio hermenéutico central: no podemos apoyar textos bíblicos ni lecturas que fomenten la violencia, a dominación, la extracción y ni la destrucción de los miembros de la naturaleza.

Como dice el profesor Ramírez-Kidd, la Biblia es una ventana para mirar la vida y sus experiencias. La lectura ecológica, por ende, puede permitir ver el texto, ver nuestras propias experiencias y proyectos de vida, llevando a reflexionar y construir mejores sendas para el futuro. Génesis 2,4-3,24, como relato modélico, nos permite ver la situación de abuso entre dos seres creados y conectados. La agresión del uno por el otro, del Adam que toma hasta secar a su compañera Adamah, nos advierte y nos recuerda el peligro de tomar sin saciedad, hasta que la tierra no pueda dar más y nos expulse definitivamente. El relato, de tinte mitológico, tiene el poder de promover la reflexión de una situación que vuelve una y otra vez a desafiar al ser humano. Isaías, por otro lado, permite denunciar los sistemas injustos, las dinámicas opresivas y coloniales, y soñar con la posibilidad de que estos sistemas caigan. Cuando lo hagan, la tierra entonará un canto de júbilo. 


\title{
Bibliografía
}

Boletín Informativo el Picudo. No 5, Noviembre, 2009.

Brueggemann, Walter. "Trajectories in Old Testament Literature and the Sociology of Ancient Israel", en N. Gottwald and Horsley, R., Hermeneutics of Liberation: Political and Social Hermeneutics. New York: Orbis Books. 1993, 201-226.

Croatto, José Severino. "La vida de la Naturaleza en Perspectiva Bíblica (Apuntes para una Lectura Ecológica de la Biblia)", en Ribla, No 21, 47-56.

De Wit, Hans. En la Dispersión el Texto es Patria: introducción a la hermenéutica clásica, moderna y postmoderna. San José: SEBILA, 2011.

Dietrich Luiz-José. "Pautas para uma Hermenéutica Ecológica: A Solidariedade abarcando todas as formas de vida", Encuentros Teológicos No 46, ano 22 / No 1, p.77-88.

Ellacuría, Ignacio. "Historicidad de la salvación cristiana", en Sobrino, J. / Ellacuría, I., Misterium Liberationis: Conceptos Fundamentales de la Teología de la Liberación. Madrid: Trotta, 1990, 323-372.

Gottwald, Norman. The Tribes of Yahweh: A Sociology of the Religion of Liberated Israel, 1250-1050 BCE. Nueva York: Maryknoll, 1979.

Habel, Norman. "Introducing Ecological Hermeneutics", en N. Habel Trudinger, P., Exploring Ecological Hermeneutics. Atlanta: Society of Biblical Literature, 2008.

Hasel, Michael. "The Destruction of Trees in the Moabite Campaign of 2 Kings 3.4-27: A Study in the Laws of Warfare", en Andrews University Seminary Studies, Vol 4, No 2, 197-206.

Mosala, Itumeleng. 1989. Biblical Hermeneutics and Black Theology in South Africa. Michigan: William Eerdmans Publishing Company.

Oliveros, Roberto, "Historia de la Teología de la Liberación", en Sobrino,

J. Y Ellacuría, I., Misterium Liberationis: Conceptos Fundamentales de la Teología de la Liberación. Madrid: Trotta, 1990, 17-50.

Ramírez-Kidd, José Enrique. Para Comprender el Antiguo Testamento. San José: SEBILA, 2009.

Rogerson, John. Genesis 1-11. New York: T \& T Clark, 2004.

Zizek, Slavoj. Pedir lo Imposible. Buenos Aires: Akal, 2014.

\author{
David Castillo \\ pandolfocm@yahoo.com
}

